\title{
How Not to Miss a Case of Malaria in Emergency Department in Malaria Non-Endemic Areas? Practical Approach \& Experiences in Hong Kong
}

\author{
Iris Wai Sum Li1,2*, Louis Chin Pang Cheung3 \\ ${ }^{1}$ Queen Mary Hospital, Hong Kong, China \\ ${ }^{2}$ School of Public Health, Li Ka Shing Faculty of Medicine, The University of Hong Kong, Hong Kong, China \\ ${ }^{3}$ Union Emergency Medicine Centre, Union Hospital, Hong Kong, China \\ Email: ^irisli.irisli.irisli@gmail.com
}

How to cite this paper: Li, I.W.S. and Cheung, L.C.P. (2016) How Not to Miss a Case of Malaria in Emergency Department in Malaria Non-Endemic Areas? Practical Approach \& Experiences in Hong Kong. Open Journal of Emergency Medicine, 4, 93-109.

http://dx.doi.org/10.4236/ojem.2016.44012

Received: November 23, 2016

Accepted: December 27, 2016

Published: December 30, 2016

Copyright $\odot 2016$ by authors and Scientific Research Publishing Inc. This work is licensed under the Creative Commons Attribution International License (CC BY 4.0).

http://creativecommons.org/licenses/by/4.0/

\section{(c) (i) Open Access}

\begin{abstract}
Human malaria is a life-threatening mosquito-borne protozoan parasitic infection in human involving female anopheline mosquitoes as vector for transmission. It is caused by Plasmodium species, most commonly, $P$. vivax, $P$. ovale, $P$. malariae and $P$. falciparum, and rarely $P$. knowlesi. Malaria remains a significant global health issue and is a medical emergency. It is also an important cause of morbidity and mortality in endemic areas, particularly in at-risk groups. In Hong Kong, where malaria is non-endemic, more than 20 cases of malaria per year have been notified in recent years. We still have chances encountering patients with malaria presented to public or private emergency departments. High index of clinical suspicious is utmost important for not missing a case of malaria. A practical approach for prompt identification of patients with severe malaria is essential, followed by appropriate initiation of appropriate effective antimalarial treatment within 24 to 48 hours of symptoms onset after blood taken for thick and thin smears for diagnosis. Vigilance with increased awareness of not falling into common diagnostic traps has to be alerted. The risk of missing any case of malaria presenting to emergency department could be largely minimized.
\end{abstract}

\section{Keywords}

Malaria, Plasmodium falciparum, Plasmodium species, Uncomplicated Malaria, Severe Malaria 


\section{What Is Malaria?}

Human malaria is a life-threatening mosquito-borne protozoan parasitic infection in human caused by Plasmodium species, most commonly, $P$. vivax, $P$. ovale, $P$. malariae and $P$. falciparum [1] [2] [3]. P. knowlesi which causes primate malaria has been found to cause human infections [2] [4].

The route of transmission is mainly through infected female Anopheline mosquitoes taking blood meal from and inoculating parasites to human and infecting their erythrocytes [1] [2] [5]; other routes of transmission in human include blood transfusion, organ transplantation, shared use of contaminated needles or syringes, and maternalto-child transplacental or perinatal transmission [6] [7] [8].

After incubation period of 6 days to up to 1 year, depending on different species of Plasmodium, malaria manifest clinically in a spectrum; from non-specific uncomplicated symptoms of acute febrile illness, intermittent fever, chills, sweating and headache, with or without anaemia and jaundice, to severe complication with seizure, confusion, coma, renal failure, shock, acute respiratory distress syndrome and death [1] [2] [3] [5] [9].

In human malaria, the life cycle of Plasmodium species (Figure 1) involved hepatic and erythrocytic infection [1] [2] [5]. And due to the cyclical parasitaemia, patients often report experiencing symptoms every 48 hours (in Plasmodium falciparum, Plasmodium vivax and Plasmodium ovale infection) to 72 hours (in Plasmodium malariae infection) [1] [5].

Globally, despite the incidence and death rate of malaria have been decreasing in recent decades, malaria remains an important cause of morbidity and mortality in endemic areas [6]. It is estimated that about 3.2 billion people, that is almost half of the world's population are at risk of malaria (Figure 2) [1] [6]. The most at risk groups are young children, pregnant women, non-immune travelers from malaria-free areas and patients co-infected with HIV [1] [5] [6].

Plasmodium vivax and $P$. falciparum malaria are the most important cause of malaria. Falciparum malaria is the most severe form of malaria leading to deaths [5] [10], vivax malaria is considered with increasingly importance as a cause of severe malaria and sometimes mortality [11]. The mechanism of severe malaria in Plasmodium falcifarum infection is mainly due to cytoadherence and then sequestration of $P$. falcifarum-infected erythrocytes leading to occlusion of blood flow resulting in decrease oxygen delivery to tissues and end organ damage (Figure 3) [5] [10] [12].

\section{Why Do We Need to Be Aware of Malaria? Experiences in Hong Kong}

Hong Kong is a malaria non-endemic area; while Sub-Saharan Africa carries a disproportionately high share of the global malaria burden, and $P$. falciparum is the most prevalent malaria parasite [5] [6]. We still have to be vigilant to maintain a high index of suspicion, conduct a thorough history including travel history, and interpret the constellations of symptoms and signs, and preliminary investigation findings accordingly 


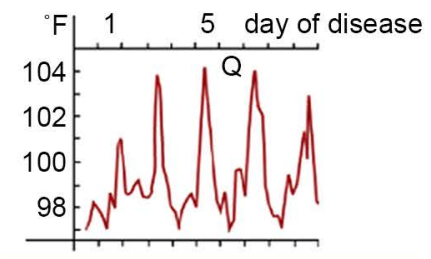

Elevated core body temperature

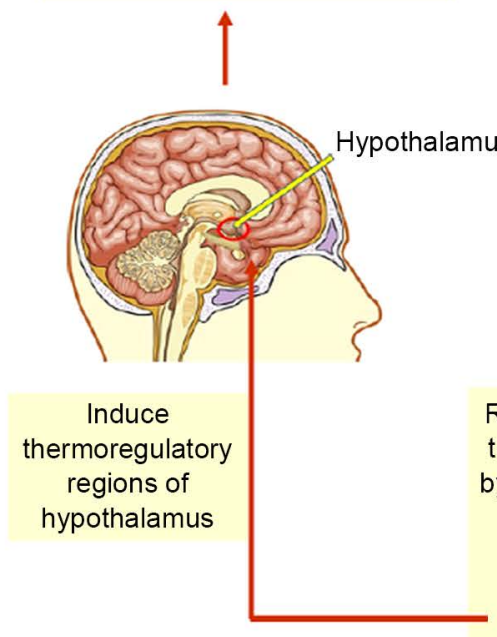

Life cycle of Plasmodium species infection in human and proposed mechanism of fever induction in malaria

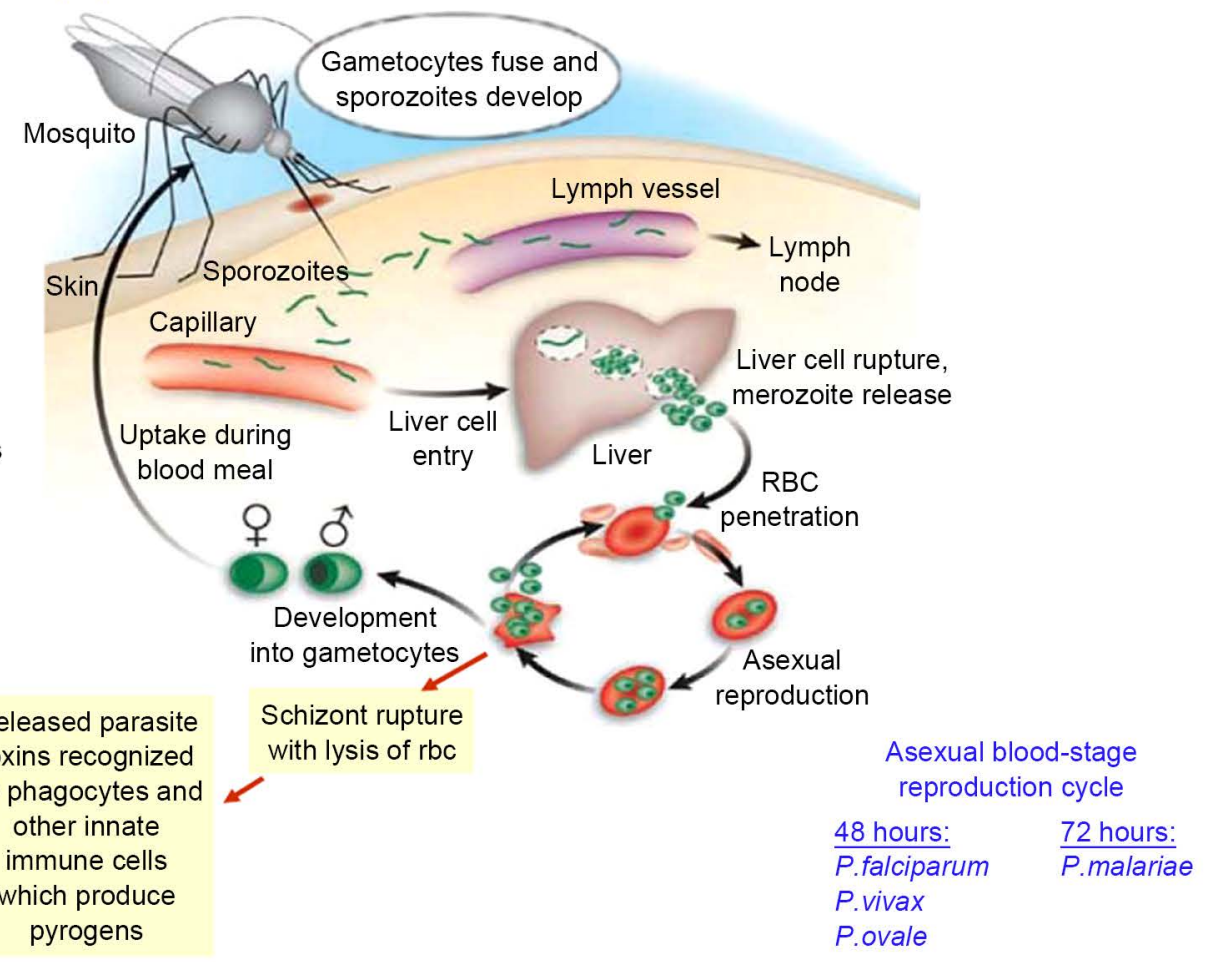

Figure 1. Life cycle of malaria infection in human and proposed mechanism of fever induction. Adapted from [5] [12] [13]. In human malaria, the life cycle of malaria involved hepatic and erythrocytic infection. When an infected female anopheline mosquito bite and take a blood meal from human, the sporozoites released from the mosquito are carried to human liver cells where multiplication take place and then exit into the bloodstreams as merozoites, which infect other erythrocytes in the blood stream to start the asexual blood-stage cycle. This cycle completes in 48 to 72 hours, depending on the infecting Plasmodium species. The process of Plasmodium species infecting erythrocytes, and its associated inflammatory response elicited, correlates with the development of clinical symptoms. These infected erythrocytes are then phagocytosed by the spleen, which intended to clear the infection, but through cytoadherence and sequestration that also lead to profound anaemia and folic acid deficiency.

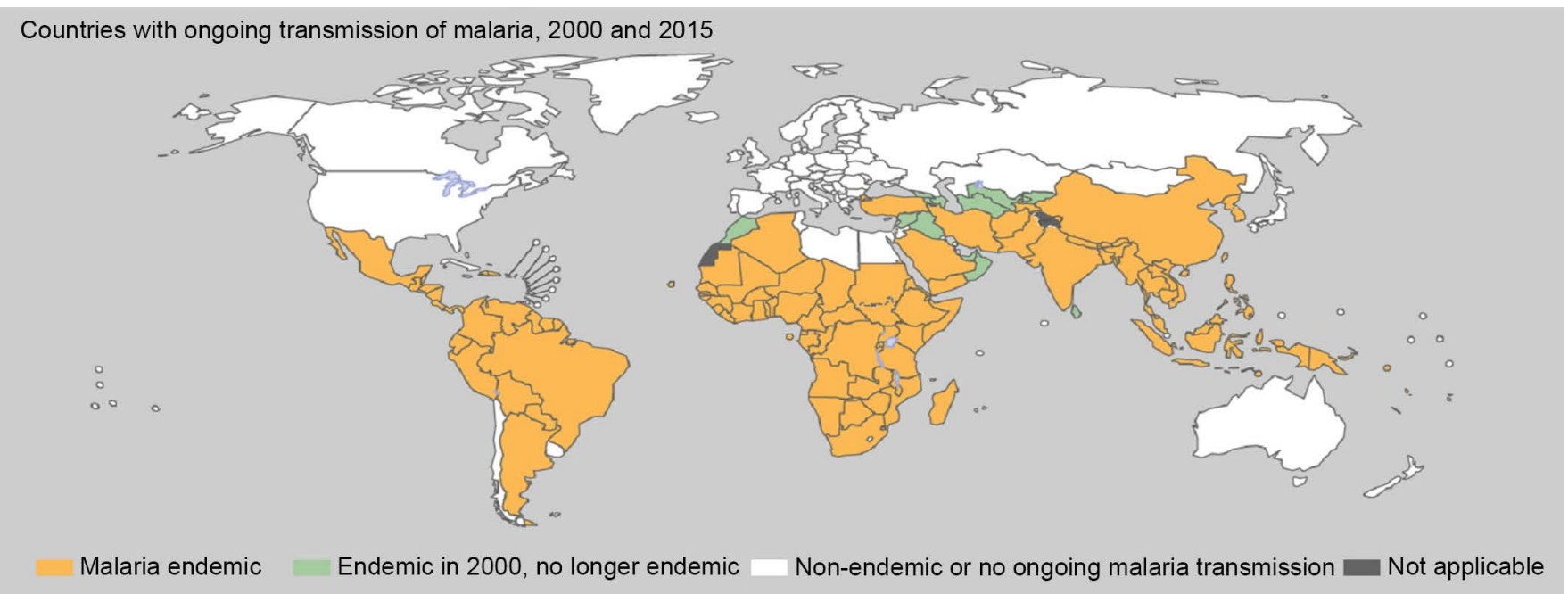

Figure 2. Countries with ongoing transmission of malaria, 2000 and 2015 [6]. 
Pathophysiology of Severe Malaria, in particular Plasmodium falciparum,

Sequestration due to Cytoadherence and Rosetting

Augmented Sequestration

Removal of infected erythrocytes from

Periphery circulation

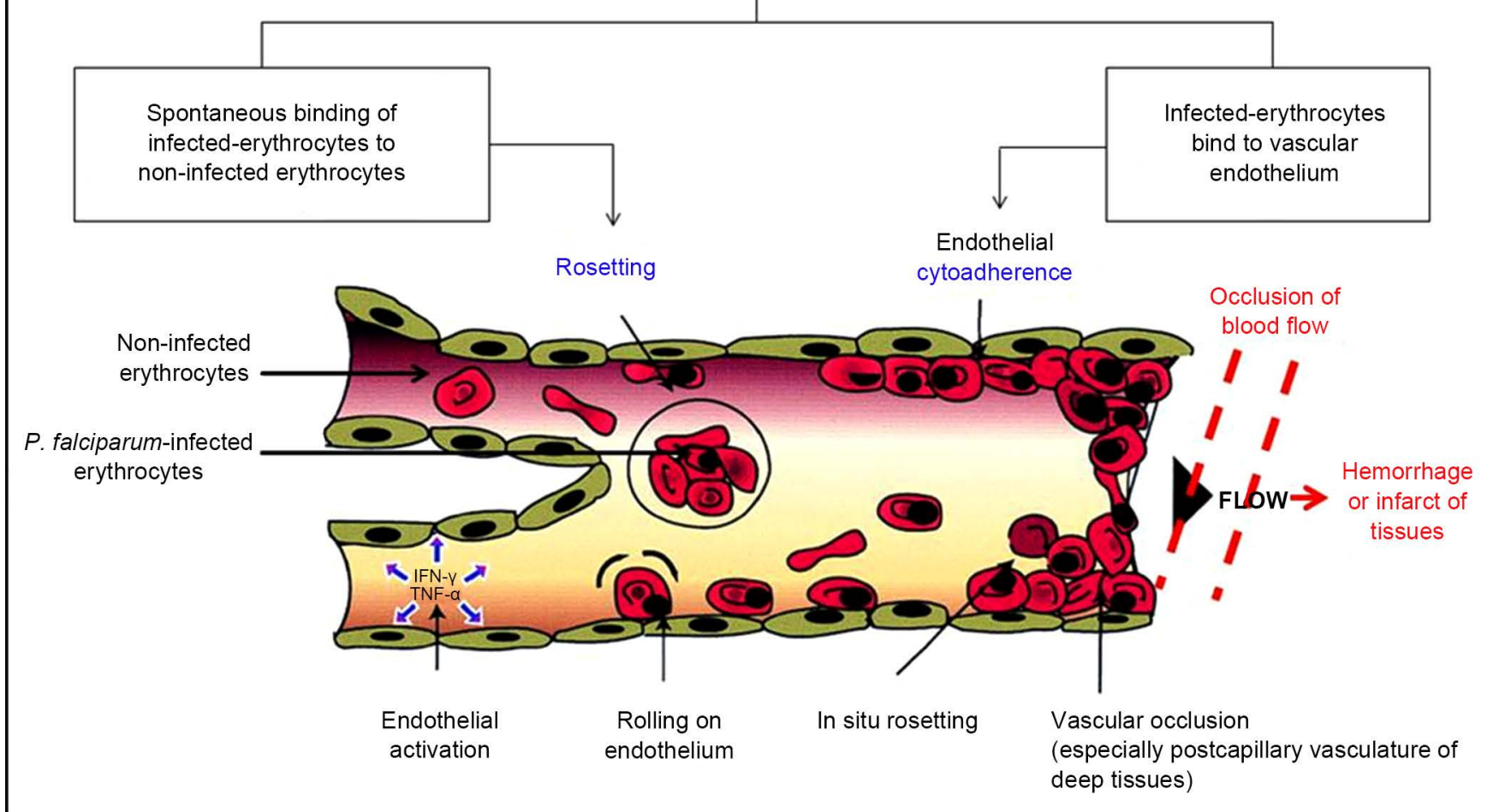

Figure 3. Pathophysiology of severe malaria, particularly in Plasmodium falciparum infection-sequestration of infected erythrocytes due to cytoadherence and rosetting. Adapted from [5] [10] [13]. In Plasmodium falciparum infection, the infected erythrocytes are capable to roll on and cytoadhere themselves via respective receptors to vascular endothelial wall. This leads to sequestration of infected cells in small blood vessels, and subsequent hemorrhage or infarct resulting in end organ damage. The spontaneous binding of uninfected erythrocytes to the infected erythrocytes also contributes to the vessel occlusions. The parasite antigens stimulate the release of interferon- $\gamma$ and tumor necrosis factor- $\alpha$ in addition to immunoglobulin complexes production.

to initiate prompt and appropriate management [12]. It is because malaria is a lifethreatening condition, which is preventable by appropriate prophylaxis and measures and treatable with prompt appropriate effective treatment within 24 to 48 hours of symptom onset [4] [5].

\section{Case presentation-Have you encountered similar situations?}

A 36-year-old lady presents to an emergency department of Hong Kong with on and off fever for 10 days with chills without other symptoms. She is a Nigerian lawyer living in Hong Kong for 3 years. She travels frequently between Hong Kong and Nigeria. She has just visited her family and returned from Nigeria, and her symptoms were actually developed during her stay in Nigeria. Her past medical history include malaria diagnosed few months prior symptom onset and has been treated with 3 days of medication; however she cannot recall any names of infecting parasite species and medica- 
tions. She is currently pregnant at 26 weeks gestation. Her drug allergy history includes augmentin, gabapentin and chloroquine. What would you do and how would you manage this patient?...

\section{Malaria in Hong Kong}

Malaria is a notifiable infectious disease in Hong Kong and has been well controlled over decades that around 20 to 30 cases of malaria per year have been notified for the last few years (Figure 4) [13] [14] [15]. Therefore, we still have chances encountering patients with malaria presented to private or public emergency departments. Majority of these patients were Hong Kong residents followed by tourists/transients, migrants and immigrants; almost half of them had travelled to and considered as imported cases from India, Pakistan and Nepal [3]. Other imported cases by country were from Africa, Southeast Asia \& Pacific Islands, Latin \& South America, and the Mainland China [3]. Majority of these malaria-infected Hong Kong residents acquired the infection during travel and amongst more than $80 \%$ of them did not have pre-travel chemoprophylaxis taken [3].

In Hong Kong, the clinical presentation of patients with malaria presented to emergency department usually non-specific which overlaps with symptoms of other diseases associated with other mosquito-borne illnesses or other conditions that commonly found in returned travelers [3] [12].

Similar to the global situation, about 1/3 of malaria cases notified in Hong Kong were due to $P$. vivax, followed by $P$. falciparum, the rest were by $P$. malariae and $P$. ovale. Mixed infections of two or more parasites have also been observed [3].

Moreover, appropriate local malaria vectors are present in Hong Kong, the female

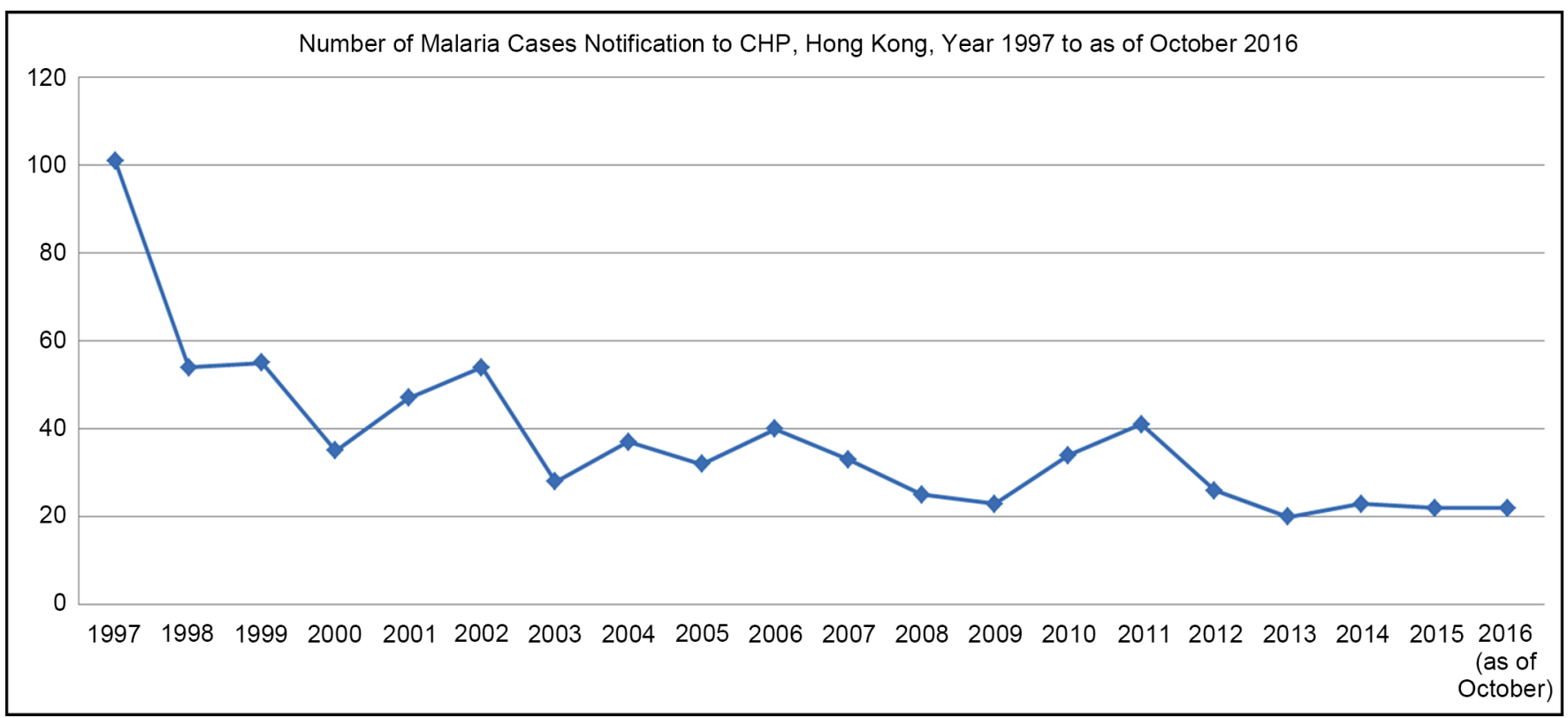

Figure 4. Number of malaria cases notification to Centre for Health Protection (CHP), Department of Health, the Government of the Hong Kong Special Administrative Region (Hong Kong) [15]. 
anopheles mosquitoes, including Anopheles jeyporiensis which breed in paddy field, waterlogged field and stream, and Anopheles minimus which breed along slow running, unpolluted stream with diffused sunlight and marginal vegetation [3] [16]. The presence of these vectors theoretically allows malaria transmission in Hong Kong when they take blood meals from patients with malaria and parasitaemia.

\section{What Can We Do in Emergency Departments for Diagnosis of Malaria?}

Malaria is a medical emergency and making diagnosis of malaria in emergency department is challenging [12]. In general, with background clinical knowledge on malaria, a high index of clinical suspicion is the utmost importance in assessment of anyone with fever or history of fever, and has returned from or previously visited a malaria-endemic area. And do not assume malaria can be excluded from diagnosis just simply by history of anti-malaria chemoprophylaxis use or history of a negative test for malaria.

Be aware of the non-specific presenting symptoms of malaria, most commonly fever, headache and generalized malaise, followed by gastrointestinal disturbances, jaundice or respiratory symptoms [3] [4] [12]. These are often misdiagnosed as non-specific viral infection, especially in children whose presentation is even particularly vague [4].

For those with uncomplicated malaria, the unremarkable findings in physical examination, and the temperature measured at single or a few time points only during the short period stay in emergency department, are not only unable to completely reveal any specific fever pattern, but also would have perpetuated the overlooking of malaria as diagnosis. Patients with severe malaria present late may present with confusion, seizures or jaundice, and in children, hepatomegaly or splenomegaly may be palpable [4] [12].

The basic history taking including travel history, physical examination and preliminary findings are our tools to minimize the chance of missing a case of malaria [9] [12]. At the same time, it is important to go through the respective lists of differential diagnosis of common causes of fever in returned travelers, and other vector-borne infection presented with fever and various clinical syndromes accordingly. These include typhoid, rickettsiosis, leptospirosis, hepatitis, influenza, HIV, dengue, agents of viral hemorrhagic fever, meningitis and encephalitis [12].

\section{Assessment of Patients with Suspected Malaria-A Practical Approach}

Upon approach to patients, general examination of the patient and assessment of vital signs including blood pressure, pulse, oxygen saturation, rapid measurement of glucose and haemoglobin levels by glucometer and haemocue respectively, are important to ascertain the haemodynamic stability of patient and to determine whether immediate resuscitation and management is the prime priority. Rapid assessment of airway, breathing and circulation are essential, in addition to mental state examination coupled with immediate establishment of intravenous access, monitoring and management of the 
abnormal vital signs accordingly whenever clinical indicated.

\section{History and Physical Examination}

It is important to identify those at-risk of having malarial infection and secondary complications. These include patients at age of extremities, pregnancy, history of blood transfusion, organ transplantation, shared use of contaminated needles or syringes, HIV infection, and travel history [6] [7] [8]. It is particularly important to diagnose malaria in pregnancy because higher rates of poor maternal outcomes including profound maternal anaemia, cerebral malaria, severe malaria and maternal mortality, in addition to poor fetal or neonatal outcomes including abortion, stillbirths, preterm delivery and low birth weight, congenital malaria and neonatal mortality have been reported [5] [11]. Moreover, expertise of critical care medicine has to be urgently consulted for admission of these patients for subsequent monitoring and management in collaboration with obstetricians [5].

\section{Why Do We Need to Take Travel History?}

Travel history including country and area of travel, stopovers and date of return, is particularly informative especially when travel history to malaria endemic areas could be elicited [11]. Not only has it raised our clinical alertness in considering malaria as possible diagnosis, it gives a clue to the likelihood of infecting Plasmodium species. It is because $P$. falciparum is considered to be the most prevalent malaria parasite on the African continent, and is most likely to occur within 3 months or no later than 6 months of return from an endemic area, while $P$. vivax in many countries outside of Africa, $P$. vivax and $P$. ovale commonly present later than 6 months after return [1] [6].

Moreover, travel history also gives clues to the likelihood of the antimalarial resistance of the infecting Plasmodium species, the effectiveness of antimalarial chemoprophylaxis if any have been taken pre- and or during travel; both of which have clinical implications on subsequent selection of appropriate antimalarial treatment for prompt management [4] [11] [16].

Chloroquine-resistant Plasmodium falciparum malaria have been documented in Caribbean (Haiti and Dominican Republic) and Central America (Mexico, Belize, Guatemala, Honduras, El Salvador, Nicaragua, Costa Rica, northwest of Panama); while mefloquine-resistant Plasmodium falciparum malaria in South America (southeast Panama, Columbia, Venezuela, Ecuador, Peru, Brazil and Bolivia), and Southeast Asia (eastern Myanmar, Thailand, Cambodia and southern Vietnam) \& Oceania [16]. For those who have travelled to border areas of Thailand, Cambodia, and Myanmar are particularly at the highest risk for multiple drug resistant infections [4] [17].

With further emergence of antimalarial drug resistance, extreme cautious is needed to those with suspected malaria and with travel history to the 5 countries of the Greater Mekong subregion: Cambodia, Lao People's Democratic Republic, Myanmar, Thailand and Viet Nam, because artemisinin resistance has been found in these areas [4] [16]. And multi-drug resistant $P$. falciparum have been found in parts of Cambodia and 
Thailand [4] [17].

In addition, travel history gives clues for risk assessment regarding the effectiveness of preventive measures. Insecticide resistances have been reported in malaria-endemic areas of sub-Saharan Africa and India [4].

\section{Investigation}

Without any delay, whenever malaria is suspected, blood taking for $1-5 \mathrm{ml}$ blood sample in EDTA tubes prior to initiation of anti-parasitic therapy, and urgently sending for thick and thin smear for microscopic examination by experienced microscopists is the most important investigation to be performed [4] [12]. The result is expected to be available within 2 hours upon laboratory receipt of specimens [4] [12]. Clinicians must not hesitate to contact and communicate with laboratory colleagues for urgent test and whenever results not readily available after a reasonable time frame [12]. Remember to note the result of percentage of red blood cells that are parasitized in falciparum malaria [4] [9].

In situations where and when there is lack of expertise in the laboratories, particularly out of hours, commercially available rapid diagnostic tests (RDT) play the role for prompt diagnosis (Figure 5). These are based on immunochromatography, which depends on different kits of RDTs, to detect Plasmodium species antigen, histidine-rich protein II (HRP-2) or enzymes such as Plasmodium lactate dehydrogenase (pLDH) and adolase, are commonly used in some laboratories in Hong Kong and other malaria non-endemic countries such as the United States and the United Kingdom [4] [18] [19] [20]. These tests are easy to perform requiring low skill levels with results readily available within 20 minutes [16]. It has been shown that RDT for malaria is superior to a single set of blood smears performed in laboratories, and its use has been advocated for rapid diagnosis or exclusion of $P$. falciparum malaria, especially for evaluation of patients with compatible clinical contexts in outpatient settings [18]. RDTs for detecting Plasmodium falciparum HRP-2 can also be useful for patients with negative blood smears resulted from recent exposure but inadequate dose of artemisinin derivatives [4]. However, mis-identification of Plasmodium falciparum malaria as non-falciparum malaria by RDT has been occurred in non-endemic area during evaluation of returned traveler from endemic area, and revealed by subsequent blood smears examination [18]. Moreover, false negative result may occur in patients with very high parasitaemia due to prozone effect [19]. Nevertheless, the use of RDT does not exclude the must tests of thick and thin smears as investigation for suspected malaria [12] [18] [20].

Moreover, molecular diagnosis with qualitative and/or quantitative analysis by species-specific polymerase chain reaction (PCR) is considered as adjunct in initial diagnosis of malaria when species determination cannot be made from blood smears [20]. Likewise, it cannot replace the must tests of thick and thin smear because the turnover time of PCR is currently still not within the clinically comparable and relevancy for acute diagnosis of malaria, despite of its high sensitivity at detection limit 5 parasites/ $\mu \mathrm{l}$ and high specificity [20]. 


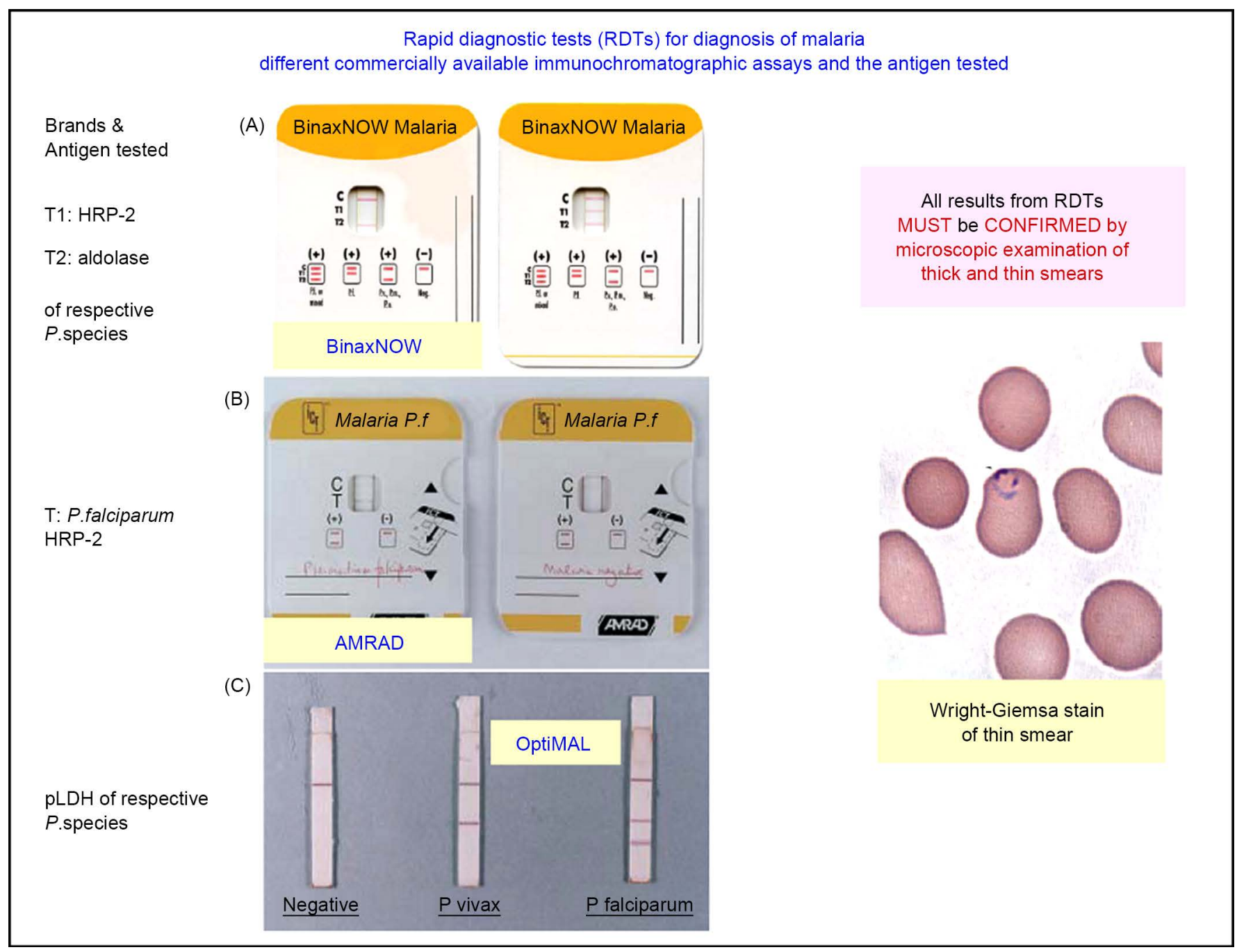

Figure 5. Different commercially available rapid diagnostic tests (RDTs) for diagnosis of malaria and the antigen tested. Adapted from [19] [20] [21]. BinaxNOW is the only brand that the U.S. Food and Drug Administration (FDA)-approved RDT for diagnosis of malaria in the United States. All results from RDTs must be confirmed by microscopic examination of thick and thin smears. The BinaxNOW RDTs (A, left) showed a faint line in the aldolase (T2) and control window, suggestive of infection due to Plasmodium vivax, $P$. malariae or $P$. ovale, and lines indicating HRP-2 (T1), aldolase (T2), and control window are present (A, right), suggestive of $P$. falciparum or mixed infection; Wright-Giemsa-stained thin smear showing classic thin, delicate ring trophozoite, supporting $P$. falciparum infection.

The microscopic examination of thick smear is highly sensitive with detection limit 50 parasites/ $\mu$ l which is equivalent to $0.001 \%$ of red blood cell infected, and a large volume of blood could be screened, as compared to the detection limit of $>100$ parasites/ $\mu$ in RDT kits [20]. Thin smear takes the advantages of preservation of morphology of parasites in erythrocytes that allow species identification under microscopic examination [20].

The initial negative blood smears does not exclude the diagnosis of malaria. Whenever clinical suspicious of malaria, repeat blood smears whenever the temperatures spike up, and for the second sets of thick and thin smears at 6 to 12 hours after the initial tests, the third sets at 12 to 24 hours after the second sets [4] [9]. Negative smears 
must be interpreted with cautions for pregnant patients because of placental sequestration of parasites, and in other high-risk groups with suspicious of malaria [9]. Negative or delay of parasitological diagnosis should not delay an immediate start of antimalarial treatment [4].

Other blood tests including i-stat point-of-care blood gas analyses, laboratory investigation of complete blood picture, clotting profiles, liver and renal function tests, random glucose, lactate and $\mathrm{pH}$ should also be taken and monitored [12]. Blood for glucose-6-phosphate dehydrogenase (G6PD) status is needed in selection of antimalarial treatment, because primaquine which used for elimination of hypnozoites from liver can cause haemolysis in G6PD deficient patients [9]. Baseline electrocardiography and chest X-ray are needed as well. Blood culture and other investigations should be undertaken accordingly for diagnosis or rule out other differential diagnosis high on the list [12].

\section{Clinical Pathway for Management of Patients with Malaria in Emergency Department}

After clinical assessment of symptoms and signs, with the presence of preliminary laboratory parameters, these allow identification and differentiation of patient with severe from uncomplicated malaria; these in turns guide the initial antimalarial treatment [12]. Severe malaria is characterized by organ damage or hematological abnormalities, and those with poor prognosis and require admission to intensive care unit can also be identified and stratified [12].

Major features of severe falciparum malaria in adults include shock with blood pressure $<90 / 60 \mathrm{mmHg}$, hypoglycaemia with blood glucose $<2.2 \mathrm{mmol} / \mathrm{L}$, haemoglobinuria, haemoglobin $\leq 8 \mathrm{~g} / \mathrm{dL}$, impaired consciousness or seizures, pulmonary edema or acute respiratory distress syndrome, spontaneous bleeding or disseminated intravascular coagulation, renal impairment with oliguria $<0.4 \mathrm{ml} / \mathrm{kg}$ body weight or creatinine $>$ $265 \mu \mathrm{mol} / \mathrm{L}$, acidosis with $\mathrm{pH}<7.3$ [4] [9] [12].

Severe malaria in children are characterized by hypoglycaemia with blood glucose < $2.2 \mathrm{mmol} / \mathrm{L}$, severe anaemia with haemoglobin $<8 \mathrm{~g} / \mathrm{dL}$, impaired consciousness or seizures, respiratory distress or acidosis with $\mathrm{pH}<7.3$, prostration, presence of parasitaemia $>2 \%$ red blood cells parasitized [4] [9].

The distinction between falciparum and non-falciparum malaria is also important, as life-threatening infection is commonly seen in the former, and the urgent initial antimalarial treatment regimen differs (Table 1) [4] [9] [17].

\section{Supportive Management}

Supportive management in emergency department settings is crucial. Antipyretics should be considered if the core temperature $>38.5^{\circ} \mathrm{C}$ [4] [12]. Paracetamol at a dose of $15 \mathrm{mg} / \mathrm{kg}$ body weight every 4 hourly given orally or as rectal suppository for young children is safe and well tolerated, and a more rapid fever clearance time had been observed when used in combination with quinine as treatment for uncomplicated 
Table 1. Antimalarial regimens for severe and uncomplicated malaria [4] [17] [23].

\begin{tabular}{|c|c|c|c|c|}
\hline & \multicolumn{3}{|c|}{ Sanford Guide version 1.8} & \multirow{2}{*}{ WHO 2015} \\
\hline & \multicolumn{2}{|c|}{ Primary treatment } & Alternatives & \\
\hline \multirow{12}{*}{ Severe malaria } & Doxycycline $100 \mathrm{mg}$ intravenous & Doxycycline $4 \mathrm{mg} / \mathrm{kg}$ [if body weight & \multirow{12}{*}{$\begin{array}{l}\text { Substitute clindamycin } \\
10 \mathrm{mg} / \mathrm{kg} \text { IV loading } \\
\text { dose, then } 5 \mathrm{mg} / \mathrm{kg} \text { IV } \\
\text { or po every } 8 \text { hourly } \\
\text { for } 7 \text { days instead of } \\
\text { doxycycline in } \\
\text { pregnant women }\end{array}$} & \multirow{7}{*}{$\begin{array}{l}\text { IV or intramuscular } \\
\text { artesunate for at least } 24 \\
\text { hours and until they can } \\
\text { tolerate oral medication, } \\
\text { then complete } \\
\text { artemisinin-based } \\
\text { combination therapies } \\
\text { (ACT, see below) for } 3 \\
\text { days (add single dose } \\
\text { primaquine in areas of } \\
\text { low transmission). }\end{array}$} \\
\hline & (IV)/oral (po) every 12 hourly for & $(\mathrm{BW})<45 \mathrm{~kg}]$ or $100 \mathrm{mg}$ (if $\mathrm{BW} \geq 45 \mathrm{~kg}$ ) & & \\
\hline & 7 days, AND & every 12 hourly IV/po for 7 days, AND & & \\
\hline & [10 mg/kg (salt) IV over 1 - 2 hours & as for adults & & \\
\hline & then $0.02 \mathrm{mg} / \mathrm{kg} / \mathrm{min}$ by constant & & & \\
\hline & $\begin{array}{l}\text { infusion] or }(24 \mathrm{mg} / \mathrm{kg} \text { IV over } 4 \text { hours, } \\
\text { then } 12 \mathrm{mg} / \mathrm{kg} \text { over } 4 \text { hours every }\end{array}$ & OR & & \\
\hline & $\begin{array}{l}8 \text { hourly). } \\
\text { - continue for a minimum } 24 \text { hours or } \\
\text { until parasite density }<1 \% \text { and can }\end{array}$ & $\begin{array}{l}\text { Artesunate } 2.4 \mathrm{mg} / \mathrm{kg} \text { IV at } 0,12,24,48 \\
\text { hours continue every } 24 \text { hourly if unable } \\
\text { to take oral medication, then complete }\end{array}$ & & \\
\hline & $\begin{array}{l}\text { times a day for completion of } 3 \text { days } \\
\text { of quinidine/quinine ( } 7 \text { days if } \\
\text { Southeast Asia) }\end{array}$ & $\begin{array}{l}\text { or } \\
\text { - artemether/lumefantrine po for } 3 \text { days. }\end{array}$ & & $\begin{array}{l}<20 \mathrm{~kg}: 3 \mathrm{mg} / \mathrm{kg} \text { BW per } \\
\text { dose; }\end{array}$ \\
\hline & \multirow{2}{*}{\multicolumn{2}{|c|}{ OR }} & & Children with $>20 \mathrm{~kg}$ \\
\hline & & & & BW and adults: \\
\hline & \multirow{2}{*}{\multicolumn{2}{|c|}{$\begin{array}{l}\text { Artesunate } 2.4 \mathrm{mg} / \mathrm{kg} \text { IV at } 0,12,24,48 \\
\text { hours, then } \\
\text { - doxycycline } 100 \mathrm{mg} \text { po every } 12 \text { hourly } \\
\text { for } 7 \text { days; or } \\
\text { - atovaquone/proguanil po for } 3 \text { days; } \\
\text { or } \\
\text { - dihydroartemisinin/piperaquine po x } 3 \\
\text { days; or } \\
\text { - continue IV artesunate every } 24 \text { hourly } \\
\text { if unable to take oral medications. }\end{array}$}} & & $2.4 \mathrm{mg} / \mathrm{kg}$ BW per dose. \\
\hline & & & & $\begin{array}{l}\text { If parenteral artesunate } \\
\text { is not available, use } \\
\text { artemether in preference } \\
\text { to quinine for treating } \\
\text { children and adults with } \\
\text { severe malaria. }\end{array}$ \\
\hline
\end{tabular}

Uncomplicated/

$P$. falciparum (or species not identified)
Chloroquine-sensitive regions:

For Adults-

Chloroquine phosphate $1 \mathrm{gm}$ salt (600 $\mathrm{mg}$ base) po, then $0.5 \mathrm{gm}$ in 6 hours, then 0.5 gm daily for 2 days. Total 2500 mg salt;

OR

Hydroxychloroquine $800 \mathrm{mg}$ salt (620 mg base) po, followed by $400 \mathrm{mg}$ salt ( $310 \mathrm{mg}$ base) po at 6,24 , and 48 hours.

OR

Artemether-lumefantrine 4 tablets $(80 \mathrm{mg} / 480 \mathrm{mg}$ ) as a single dose, then 4 tablets again after 8 hours, then 4 tablets every 12 hours for 2 days
For Paediatrics-

Chloroquine phosphate $10 \mathrm{mg} / \mathrm{kg}$ of base po; then $5 \mathrm{mg} / \mathrm{kg}$ of base at 6,24 \& 48 hours. Total $25 \mathrm{mg} / \mathrm{kg}$ base (never exceed adult dose).

OR

Hydroxychloroquine $10 \mathrm{mg}$ base $/ \mathrm{kg}$ po immediately, followed by $5 \mathrm{mg}$ base $/ \mathrm{kg}$ at 6,24 , and 48 hours. Total $25 \mathrm{mg}$ base/kg.

OR

Artemether-lumefantrine

(20/120 mg tablets)

- <5 kg: not recommended;

- $5 \mathrm{~kg}$ to <15 kg: 1 tablet (20 mg/120 mg) as a single dose, then 1 tablet again
Atovaquone-proguanil 4 adult tabs $(1000 / 400$ $\mathrm{mg}$ ) po in a single dose daily $\times 3$ days (take with food);

OR

[(quinine sulfate $650 \mathrm{mg}$ po three times a day) for 3 days ( 7 days if acquired in Southeast Asia)] + [(doxycycline $100 \mathrm{mg}$ po two times a day) or (tetracycline $250 \mathrm{mg}$ po four times a day)]
For adults and pediatrics except pregnant women in $1^{\text {st }}$ trimester:

Any of the (ACT) for 3 days:

- Artemether + lumefantrine;

- Artesunate + amodiaquine;

- Artesunate + mefloquine;

- Dihydroartemisinin + sulfadoxinepyrimethamine (SP)

For $1^{\text {st }}$ trimester pregnancy: (quinine sulfate + clindamycin) for 7 days; 
(take with food)

Pyronadridine/artesunate 4 tablets (180 mg/60 mg) as a single dose each day for 3 days for $>65 \mathrm{~kg}$ or 3 tablets if $45 \mathrm{~kg}$ to $<65 \mathrm{~kg}$ after 8 hours, then 1 tablet every

12 hours for 2 days;

- $15 \mathrm{~kg}$ to $<25 \mathrm{~kg}: 2$ tablets $(40 \mathrm{mg} / 240$ $\mathrm{mg}$ ) as a single dose, then 2 tablets again after 8 hours, then 2 tablets every 12 hours for 2 days;

- $25 \mathrm{~kg}$ to $<35 \mathrm{~kg}$ : 3 tablets $(60 \mathrm{mg} / 360$ $\mathrm{mg}$ ) as a single dose, then 3 tablets after 8 hours, then 3 tablets every 12 hours for 2 days;

- $\geq 35 \mathrm{~kg}$ : as per adult dose;

Pyronaridine/artesunate 2 tablets $(180 \mathrm{mg} / 60 \mathrm{mg}$ ) as a single dose each day for 3 days for $24 \mathrm{~kg}$ to $>45 \mathrm{~kg}$ or 1 tablet if $20 \mathrm{~kg}$ to $<24 \mathrm{~kg}$.
Infant $<5 \mathrm{~kg} \mathrm{BW:} \mathrm{ACT}$ at same $\mathrm{mg} / \mathrm{kg} \mathrm{BW}$ target dose as for children with $5 \mathrm{~kg} \mathrm{BW}$;

For patients co-infected with HIV: avoid artesunate + SP if treated with co-trimoxazole, and avoid (artesunate + amodiaquine) if treated with efavirenz or zidovudine.

Non-immune travelers: ACT;

Uncomplicated hyperparasitaemia: Mefloquine $750 \mathrm{mg}$ po for 1 dose, then $500 \mathrm{mg}$ po for 1 dose 6 to 12 hours later (not effective against strains of $P$. falciparum from Southeast Asia);

- <5 kg: not recommended;

- $5 \mathrm{~kg}-8 \mathrm{~kg}: 2$ pediatric tablets in single dose daily for 3 days;

- $9 \mathrm{~kg}-10 \mathrm{~kg}: 3$ pediatric tablets in a single dose daily for 3 days;

- $11 \mathrm{~kg}$ - $20 \mathrm{~kg}: 1$ adult tablet in a single dose daily for 3 days;

OR

- $21 \mathrm{~kg}$ - $30 \mathrm{~kg}: 2$ adult tablets in a single dose daily for 3 days;

[(quinine sulfate $650 \mathrm{mg}$ po three times a $-31 \mathrm{~kg}$ - $40 \mathrm{~kg}$ : 3 adult tablets in a day for 3 days (7 days if Southeast Asia)] single dose daily for 3 days; $+[($ doxycycline $100 \mathrm{mg}$ po two times a day) or (tetracycline $250 \mathrm{mg}$ po four times a day)]

- >40 kg: as per adult dose

[(quinine sulfate $10 \mathrm{mg} / \mathrm{kg}$ po three times a day for 3 days); (7 days if

Pyronaridine/artesunate 4 tablets (180 $\mathrm{mg} / 60 \mathrm{mg}$ ) as a single dose each day for 3 days for $>65 \mathrm{~kg}$ or 3 tablets if $45 \mathrm{~kg}$ to $<65 \mathrm{~kg}$.
Southeast Asia)]+ (clindamycin $20 \mathrm{mg} / \mathrm{kg}$ per day divided in three times a day)] both for 7 days under age of 8 ;

[(qunine sulfate $10 \mathrm{mg} / \mathrm{kg}$ po three times a day for 3 days); (7 days if Southeast Asia) + (doxycycline $2.2 \mathrm{mg} / \mathrm{kg} /$ two times a day) or (tetracycline $25 \mathrm{mg} / \mathrm{kg} /$ day divided four times a day) for 7 days.

Pyronaridine/artesunate 2 tablets $(180 \mathrm{mg} / 60 \mathrm{mg})$ as a single dose each day for 3 days for $24 \mathrm{~kg}$ to $>45 \mathrm{~kg}$ or 1 tablet if $20 \mathrm{~kg}$ to $<24 \mathrm{~kg}$. 
Uncomplicated/

$P$. ovale,

P. malariae or

P. knowlesi
Chloroquine-sensitive regions:

For adults-

Chloroquine phosphate $1 \mathrm{gm}$ salt ( $600 \mathrm{mg}$ base) po, then $0.5 \mathrm{gm}$ in 6 hours, then 0.5 gm daily for 2 days. Total 2500 mg salt;

OR

Hydroxychloroquine $800 \mathrm{mg}$ salt (620 mg base) po, followed by $400 \mathrm{mg}$ salt (310 mg base) po at 6,24 , and 48 hours.

OR

Artemether-lumefantrine 4 tablets $(80 \mathrm{mg} / 480 \mathrm{mg})$ as a single dose, then 4 tablets again after 8 hours, then 4 tablets every 12 hours for 2 days (take with food)

PLUS ( $P$. ovale only) + primaquine phosphate $52.6 \mathrm{mg}$ (30mg base $=2$ tablets) po once daily for 14 days.
For paediatrics-

Chloroquine phosphate $10 \mathrm{mg} / \mathrm{kg}$ of base po; then $5 \mathrm{mg} / \mathrm{kg}$ of base at $6,24 \& 48$ hours. Total $25 \mathrm{mg} / \mathrm{kg}$ base (never exceed adult dose).

OR

Hydroxychloroquine $10 \mathrm{mg}$ base/kg po immediately, followed by $5 \mathrm{mg}$ base $/ \mathrm{kg}$ at 6, 24, and 48 hours. Total $25 \mathrm{mg}$ base/kg.

OR

Artemether-lumefantrine (20/120 mg tablets)

- $5 \mathrm{~kg}$ to <15 kg: 1 tablet $(20 \mathrm{mg} / 120 \mathrm{mg}$ ) as a single dose, then 1 tablet again after 8 hours, then 1 tablet every 12 hours for 2 days;

- $15 \mathrm{~kg}$ to $<25 \mathrm{~kg}$ : 2 tablets as a single dose, then 2 tablets again after 8 hours, then 2 tablets every 12 hours for 2 days;

- $25 \mathrm{~kg}$ to $<35 \mathrm{~kg}: 3$ tablets as a single dose, then 3 tablets again after 8 hours, then 3 tablets every 12 hourly for 2 days;

- $\geq 35 \mathrm{~kg}$ : as per adult dose;

PLUS ( $P$. ovale only)

+ Primaquine phosphate $0.5 \mathrm{mg} / \mathrm{kg}$ po base once daily for 14 days
For blood stage infection:

(also include $P$. vivax \& P. ovale)

For unknown species, treat as for uncomplicated $P$. falciparum malaria.

Chloroquine-sensitive: either ACT (except in $1^{\text {st }}$ trimester pregnancy) or chloroquine;

Chloroquine-resistant: ACT (except in $1^{\text {st }}$ trimester pregnancy, use quinine);

For preventing relapse in $P$. vivax or $P$. ovale malaria:

primaquine ( 0.25 to 0.5 $\mathrm{mg} / \mathrm{kg} \mathrm{BW}$ ), for 14 days, except pregnancy, infants aged $<6$ months, woman breastfeeding infants aged $<6$ months, women breastfeeding older infants unless they are known not to be G6PD deficient, and people with G6PD deficiency).

For G6PD deficiency: consider primaquine base $0.75 \mathrm{mg} / \mathrm{kg} \mathrm{BW}$ once a week for 8 weeks, with close medical supervision for potential primaquine-induced haemolysis.

Pregnant and breastfeeding women: consider weekly chemoprophylaxis with chloroquine until delivery and breastfeeding are completed, then on the basis of G6PD status, treat with primaquine to prevent future relapse.
OR
OR

Artemether-lumefantrine (20/120 mg tablets)
Hydroxychloroquine $10 \mathrm{mg}$ base/kg po immediately, followed by $5 \mathrm{mg}$ base $/ \mathrm{kg}$ + primaquine phosphate $0.5 \mathrm{mg}$ po base once daily for 14 days;

$\mathrm{mg}$ ( $30 \mathrm{mg}$ base $=2$ tablets) po once daily for 14 days.

Artemether-lumefantrine 4 tablets 
(80 $\mathrm{mg} / 480 \mathrm{mg})$ as a single dose, then 4 tablets again after 8 hours, then 4 tablets every 12 hours for 2 days (take with food) + primaquine phosphate $52.6 \mathrm{mg}$ (30 $\mathrm{mg}$ base $=2$ tablets) po once daily for 14 days.
- $5 \mathrm{~kg}$ to $<15 \mathrm{~kg}: 1$ tablet $(20 \mathrm{mg} / 120 \mathrm{mg}$ ) as a single dose, then 1 tablet again after 8 hours, then 1 tablet every 12 hours for 2 days;

- $15 \mathrm{~kg}$ to <25 kg: 2 tablets (40 mg/240 $\mathrm{mg}$ ) as a single dose, then 2 tablets again after 8 hours, then 2 tablets every 12 hours for 2 days;

- $25 \mathrm{~kg}$ to $<35 \mathrm{~kg}: 3$ tablets as a single dose, then 3 tablets again after 8 hours, then 3 tablets every 12 hourly for 2 days;

- $\geq 35 \mathrm{~kg}$ : as per adult dose;

+ Primaquine phosphate $0.5 \mathrm{mg} / \mathrm{kg}$ po base once daily for 14 days

Chloroquine-resistant regions: same as chloroquine-resistant as below

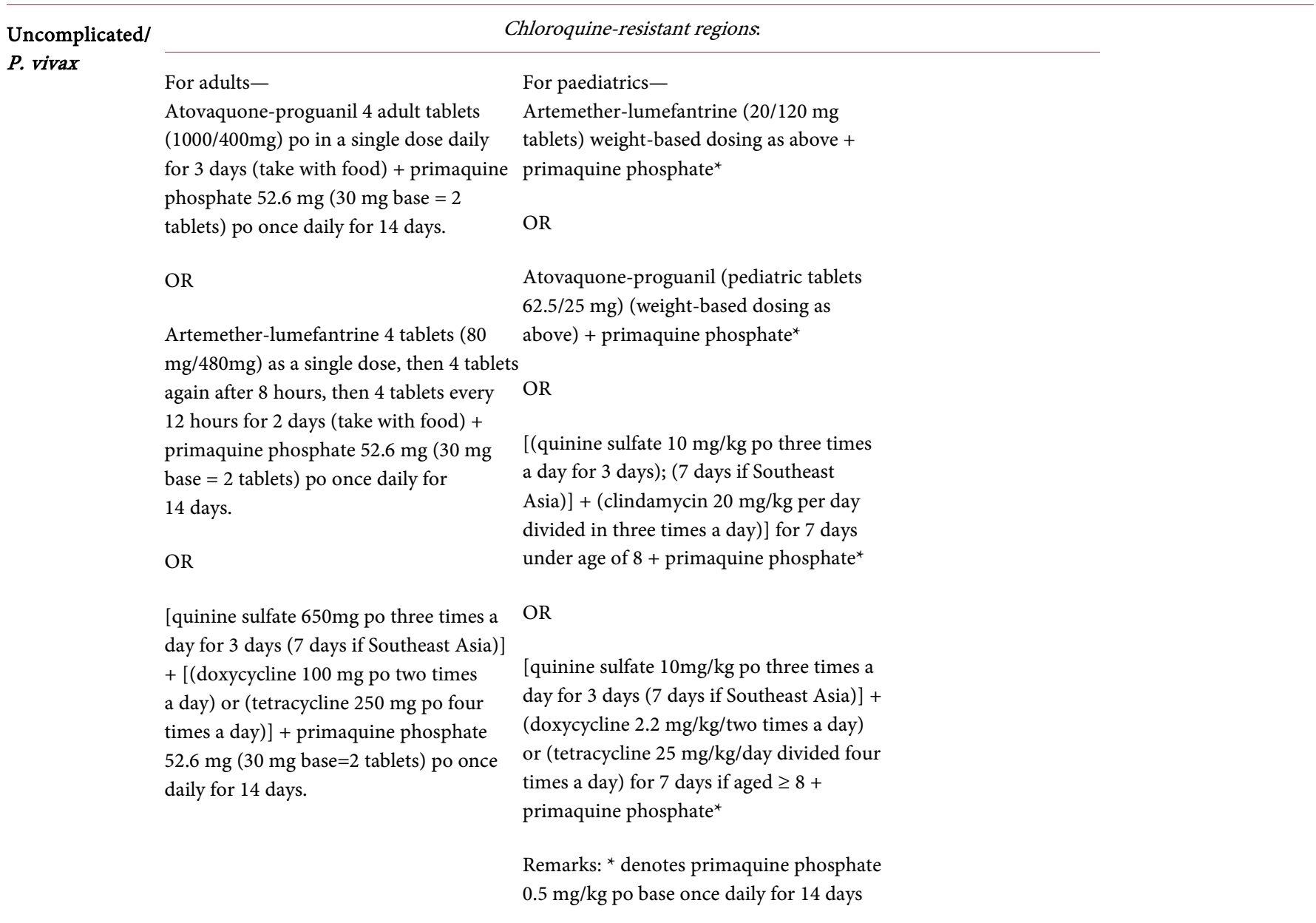

Plasmodium falciparum malaria as compared to quinine alone [4] [22]. Aspirin and non-steroidal anti-inflammatory drugs are not recommended as antipyretics for patients with suspected or diagnosed malaria because of the risk of gastrointestinal bleeding, renal impairment and Reye's syndrome [12]. 
Anti-emetic is another commonly prescribed medications in emergency departments. Cautious use of anti-emetics in patients with vomiting is needed because these potentially sedative medications, with the occurrence of their potential neuropsychiatric adverse effects, can mask the diagnosis of cerebral malaria [4] [6] [9].

Suspected patients with more than two seizures within 24 hours should be treated as severe malaria. When seizure continues, airway should be maintained and anticonvulsants, such as parenteral or rectal benzodiazepines or intramuscular paraldehyde, are needed [4].

\section{Subsequent Treatment}

The subsequent treatment regimens for severe and uncomplicated malaria due to different infecting Plasmodium species and according to the potential antimalarial resistance are also shown in Table 1 [4] [9] [17] [23].

\section{Summary}

Malaria is a medical emergency and more than 20 cases per year have been notified in recent years in Hong Kong where malaria is non-endemic. High index of clinical suspicion is utmost important for not missing such a case, followed by prompt identification of patients with severe malaria to start appropriate effective antimalarial treatment within 24 to 48 hours of symptom onset after blood have been taken for thick and thin smears for diagnosis, and admission to intensive care unit for further management.

In addition, we have to be vigilant with increased awareness of not falling into common diagnostic traps. Be aware not to rule out malaria simply based on history of chemoprophylaxis use, not to assume that the chemoprophylaxis is the correct regimen, not to assume the compliance of chemoprophylaxis, not to initiate inappropriate treatment, not to delay treatment for cases of severe malaria and not to delay treatment beyond 6 hours after Plasmodium falciparum is confirmed by laboratory test [9] [12].

Whenever in doubt, do not hesitate to contact laboratories for urgent microscopic examination of thick and thin smears for diagnosis, consult infectious diseases physicians for assessment and management, in particular when encountering at-risk groups or patients with G6PD deficiency.

When we practice in this approach, the risk of missing any case of malaria presenting to emergency departments could be largely minimized.

\section{Conflict of Interest}

All authors have no conflict of interest.

\section{References}

[1] World Health Organization (2016) Malaria, Key Facts, Symptoms, Who's at Risk, Disease Burden, Transmission, Prevention, Insecticide to Mosquito Nets, Indoor Spraying with Residual Insecticides, Antimalarial Treatment and Insecticide Resistance. http://www.who.int/mediacentre/factsheets/fs094/en/ 
[2] The U.S. Centers for Disease Control and Prevention (2016) Malaria.

http://www.cdc.gov/malaria/index.html

[3] Centre for Health Protection, Department of Health, the Government of Hong Kong Special Administrative Region (2006) Epidemiology of Malaria in Hong Kong. http://www.chp.gov.hk/files/pdf/epidemiology_of_malaria_in_hong_kong_r.pdf

[4] World Health Organization (2015) Guidelines for the Treatment of Malaria, 3rd Edition. WHO Press, World Health Organization.

[5] Schantz-Dunn, J. and Nour, N.M. (2009) Malaria and Pregnancy: A Global Health Perspective. Reviews in Obstetrics and Gynecology, 2, 186-192.

[6] World Health Organization (2015) Malaria World Report 2015 Summary. http://apps.who.int/iris/bitstream/10665/205224/1/WHO_HTM_GMP_2016.2_eng.pdf?ua $=1$

[7] The US Centers for Disease Control and Prevention (2016) Malaria Transmissions in the United States. https://www.cdc.gov/malaria/about/us_transmission.html

[8] The US Centers for Disease Control and Prevention (2016) Malaria/About Malaria/ Frequently Asked Questions. http://www.cdc.gov/Malaria/about/faqs.html

[9] Lalloo, D.G., Shingadia, D., Ben, D.J., Beeching, N.J., Pasvol, G., Chiodini, P.L., Whitty, C.J. and Chiodni, P.L., PHE Advisory Committee on Malaria Prevention in UK Travellers (2016) UK malaria Treatment Guidelines. Journal of Infection, 72, 635-649. https://doi.org/10.1016/j.jinf.2016.02.001

[10] Chen, Q., Schlichtherle, M. and Wahlgren, M. (2000) Molecular Aspects of Severe Malaria. Clinical Microbiology Reviews, 13, 439-450. https://doi.org/10.1128/CMR.13.3.439-450.2000

[11] Naing, C., Whittaker, M.A., Nyunt Wai, V. and Mak, J.W. (2014) Is Plasmodium vivax Malaria a Severe Malaria: A Systematic Review and Meta-Analysis. PLOS Neglected Tropical Diseases, 8, e3071. https://doi.org/10.1371/journal.pntd.0003071

[12] Caraballo, H. and King, K. (2014) Emergency Department Management of Mosquito-Borne Illness: Malaria, Dengue, and West Nile Virus. Emergency Medicine Practice, 16, 1-23.

[13] Oakley, M.S., Gerald, N., McCutchan, T.F., Aravind, L. and Kumar, S. (2011) Clinical and Molecular Aspects of Malaria Fever. Trends in Parasitology, 27, 442-449. https://doi.org/10.1016/j.pt.2011.06.004

[14] Centre for Health Protection, Department of Health, The Government of Hong Kong Special Administrative Region (2016) Statistics on Notifiable Infectious Diseases. http://www.chp.gov.hk/en/dns_submenu/10/26.html

[15] Centre for Health Protection, Department of Health, The Government of Hong Kong Special Administrative Region (2012) Global Malaria Risk Summary October 2012. www.chp.gov.hk/files/pdf/global_malaria_risk_summary_october_2012_r.pdf

[16] Food and Environmental Hygiene Department, the Government of Hong Kong Special Administrative Region (2016) Mosquito Pest and Their Control. http://www.fehd.gov.hk/english/safefood/risk-pest-mosquito.html

[17] Gilbert, D.N., Chambers, H.F., Eliopoulos, G.M. and Saag, M.S. (2014) The Sanford Guide to Antimicrobial Therapy 2014. 44th Edition, Antimicrobial Therapy, Incorporated, Sperryville.

[18] Stauffer, W.M., Cartwright, C.P., Olson, D.A., Juni, B.A., Taylor, C.M., Bowers, S.H., Hanson, K.L., Rosenblatt, J.E. and Boulware, D.R. (2009) Diagnostic Performance of Rapid Diagnostic Tests versus Blood Smears for Malaria in US Clinical Practice. Clinical Infectious 
Diseases, 49, 908-913. https://doi.org/10.1086/605436

[19] Dimaio, M.A., Pereira, I.T., George, T.I. and Banaei, N. (2012) Performance of BinaxNOW for Diagnosis of Malaria in a U.S. Hospital. Journal of Clinical Microbiology, 50, 2877-2880. https://doi.org/10.1128/JCM.01013-12

[20] Moody, A. (2002) Rapid Diagnostic Tests for Malaria Parasites. Clinical Microbiology Reviews, 15, 66-78. https://doi.org/10.1128/CMR.15.1.66-78.2002

[21] The U.S. Centers for Disease Control and Prevention (2016) Laboratory Identification of Parasitic Diseases of Public Health Concern. https://www.cdc.gov/dpdx/malaria/gallery.html\#pfalringformtrophs

[22] Krishna, S., Supanaranond, W., Pukrittayakamee, S., ter Kuile, F., Supputamangkol, Y., Attatamsoonthorn, K., Ruprah, M. and White, N.J. (1995) Fever in Uncomplicated Plasmodium falciparum Infection: Effects of Quinine and Paracetamol. Transactions of the Royal Society of Tropical Medicine and Hygiene, 89, 197-199.

https://doi.org/10.1016/0035-9203(95)90494-8

[23] Antimicrobial Therapy, Incorporated (2016) The Sanford Guide to Antimicrobial Therapy. Version 1.8 for Android iPhone Windows Phone iOS, Updated: 2016-08-05, Antimicrobial Therapy, Incorporated, Sperryville.

Submit or recommend next manuscript to SCIRP and we will provide best service for you:

Accepting pre-submission inquiries through Email, Facebook, LinkedIn, Twitter, etc. A wide selection of journals (inclusive of 9 subjects, more than 200 journals)

Providing 24-hour high-quality service

User-friendly online submission system

Fair and swift peer-review system

Efficient typesetting and proofreading procedure

Display of the result of downloads and visits, as well as the number of cited articles

Maximum dissemination of your research work

Submit your manuscript at: http://papersubmission.scirp.org/

Or contact ojem@scirp.org 